\title{
China's Emissions Trading Scheme: First Evidence on Pilot Stage
}

\author{
Lu Zhang, Yi Zeng, Dayuan Li* \\ Collaborative Innovation Center of Resource-conserving \& Environment-Friendly \\ Society and Ecological Civilization, School of Business, Central South University, \\ Changsha, China
}

Received: 9 November 2017

Accepted: 28 January 2018

\begin{abstract}
Greenhouse gas emissions are a worldwide concern, especially in China, who has become the largest greenhouse gas emitter. In 2013, China initiated pilot emissions trading schemes (ETS) in seven regions with the aim of creating a national system by 2017 to reduce carbon emissions at low cost. We provide a systematic overview of the practice, performance, and problems of China's ETS pilots during the first stage, which lasted from 2013 to 2016, and highlight some proposals for the forthcoming national system. We depict the features of the pilots by focusing on the core elements of the ETS: scope, cap setting, allocation, MRV, and compliance. The performance of China's ETS pilots is characterized by low carbon prices with severe temporal fluctuation, and low levels of liquidity with high compliance rates. The problems include over-allocation of emission allowances, inadequate legal and regulatory infrastructure, underdevelopment of the carbon financial market, and poor market transparency. Accordingly, we propose recommendations from the perspective of legislation, cap setting, transparency, price management, and policy coordination.
\end{abstract}

${ }^{1}$ Keywords: China's emissions trading schemes (CN-ETS), carbon emissions, carbon market, ETS pilots

1 Abbreviations: emissions trading schemes (ETS); China's emissions trading schemes (CN-ETS); carbon dioxide $\left(\mathrm{CO}_{2}\right)$; gross domestic product (GDP); National Development and Reform Commission (NDRC); Chinese Yuan (CNY); Chinese Certified Emissions Reduction (CCER); monitoring, reporting, and verification (MRV); greenhouse gas (GHG)

*e-mail: lidayuan@csu.edu.cn 


\section{Introduction}

Since its rapid economic development over the past three decades, China has become the largest greenhouse gas emitter, accounting for $27.3 \%$ of the world's $\mathrm{CO}_{2}$ emissions and $23.2 \%$ of global energy consumption in 2015 [1]. On the other hand, with U.S. President Donald Trump's withdrawal from the Paris Agreement on Climate Change, which sets a target of holding the global temperature rise below $2^{\circ} \mathrm{C}$ above pre-industrial levels, China is expected to play a more significant role in leading the war against climate change. So reducing greenhouse gas emissions is not only a domestic demand for a transition to a low-carbon economy, but also a commitment to the whole world of sustainable development [2]. Due to increasing domestic and international pressure, China has pledged to reduce $\mathrm{CO}_{2}$ per unit of GDP by $40-50 \%$ against 2005 levels by 2020 $[3,4]$ and to peak $\mathrm{CO}_{2}$ emissions by about 2030 .

As a step to achieve its commitment, China has turned to the market tool of emissions trading schemes, aiming to reduce carbon emission at a low cost. At the end of 2011 the National Development and Reform Commission (NDRC) introduced the Notice on Launching Pilots for an "emissions trading system." The NDRC selected seven ETS pilots, including five cities and two provinces - Shenzhen, Guangdong, Shanghai, Beijing, Tianjin, Hubei, and Chongqing - to reduce $\mathrm{CO}_{2}$ using a marketbased approach.

Since the first establishment of an ETS pilot in Shenzhen in 2013, the ETS has been one of China's key implementations in reducing greenhouse gas emissions and is evolving into a national ETS in late 2017. After that, China will become the largest carbon emissions market in the world [5]. A review of the practice and performance of the pilot schemes is necessary to provide insight toward a more effective national scheme and a method for significant $\mathrm{CO}_{2}$ reduction. This paper responds in a timely way to the demand and examines the practice, performance, and problems in the pilot stages $^{1}$ of China's ETS and provides proposals for Chinese policy makers to establish an effective national program that is appropriate for China's unique economic and social context, as well as insights for other emerging economies.

To assess the progress of the ETS pilots and propose a better nationwide ETS, by comparing the development of the pilots, we identify issues that have emerged in the design process, and put forward suggestions for the construction of the national ETS. The relevant information of this paper is obtained from the China Statistical Yearbook and the website or direct contact of the National/Local Development and Reform

\footnotetext{
Initially, the pilot stage was scheduled from 2013 to 2015 and came to an end by the national ETS in 2016. However, since the national ETS did not start before 2017, the pilot stage extends to 2016 .
}

Commission - government agencies in charge of China's ETS.

\section{Results and Discussion}

\section{Settings of China's ETS Pilots}

China announced its intention to establish an emissions trading scheme in 2011 and moved quickly toward seven regional pilot schemes in 2013 [6], aiming to provide a successful national ETS by 2017 [7]. The seven regions for the pilot schemes spread from north to south and from east to west. Some are located in less developed inner areas, such as Hubei and Chongqing, while others are located in the coastal developed regions, each with obvious differences in natural, economic, and social conditions

The pilots' geographic area accounts for $5 \%$ of China's total land mass (more than 481,000 $\mathrm{km}^{2}$ ), around $19.18 \%$ of China's population (about 256.4 million people), $29.03 \%$ of China's GDP (almost 11992.1 billion CNY) in 2010 [8], and 17.22\% of China's carbon dioxide emissions (1533 million tons). As to the industry structure, in Tianjin, Guangdong, and Hubei secondary industry accounts for the highest sector of the economy $(53.1 \%, 50.4 \%$, and $49.1 \%$, respectively, above the national average of $46.9 \%$ ), while in Beijing, Chongqing, and Shenzhen tertiary industry accounts for the highest sector of the economy $(75 \%, 46.8 \%$, and $52.4 \%$, respectively - much higher than the national average of $42.9 \%$ ).

Most of the pilots' per-capital GDP is higher than the national average (except for Hubei and Chongqing). All the pilots have a lower carbon intensity than the national average and aim to reduce their levels more than the national average of $18 \%$ in 2020 compared to 2015 .

\section{Practice of China's ETS Pilots}

Launched between 2013 and 2014, the seven ETS pilots are authorized to design their own schemes and have already completed their first stage [9]. In this section, we focus on the main elements of China's ETS, i.e., scope, cap setting, allocation, MRV, and compliance, in order to depict the features of the seven pilots.

\section{Cap Setting}

The cap is the upper limit of carbon emissions allowed in an ETS. Policy makers seek to balance environmental targets with their economic conditions in a cap setting [10]. There are two alternatives of a cap setting: an absolute cap and an intensity cap. The former limits total emissions to a fixed quantity (denoted in tons of $\mathrm{CO}_{2}$ ), while the latter restricts emissions to a specified rate relative to output (always denoted in terms of $\mathrm{CO}_{2}$ per unit of GDP). China has set intensity-based carbon emission reduction targets at both the national and 
regional levels $[11,12]$. However, the seven pilots chose an absolute cap (with the exception of Shenzhen, which adopted both an absolute and intensity cap) [13], to avoid system complexity and reduce administrative costs.

Each pilot has a unique cap design [14]. Guangdong and Chongqing set caps annually, while Tianjin and Shanghai established a fixed cap for the entirety of the pilot stage. Most of the pilots keep steady or reduce their caps in 2013 to 2016 (with the exception of Guangdong in 2014, which rose from 388 to $408 \mathrm{MtCO} 2 \mathrm{e}$, and Shanghai in 2016, which rose from 150 to $155 \mathrm{MtCO} 2 \mathrm{e}$ ). For example, Chongqing set a cap of 119, 116, 106, and $100 \mathrm{MtCO} 2 \mathrm{e}$ in 2013, 2014, 2015, and 2016, respectively. The cap settings in Guangdong and Hubei are among the highest (with a total of 1590 and $1182 \mathrm{MtCO} 2 \mathrm{e}$, respectively) since they are bigger regions with more population, higher GDP and more $\mathrm{CO} 2$, while the cap setting in Shenzhen and Beijing are the lowest (with a total of 121 and $191 \mathrm{MtCO} 2 \mathrm{e}$, respectively), because the two regions have more service industries.

With different cap settings and total emissions, the stringency of the caps on total $\mathrm{CO}_{2}$ emissions varies across pilots. During the pilot period, ETS in Beijing was the most stringent, with a value of $2.36,2.60$, and 1.95 in 2013, 2014, and 2015, respectively, while Shenzhen came second, and Hubei was the least stringent, with a value of $0.99,1.01$, and 1.23 in 2013, 2014, and 2015, respectively. However, there is a different trend in each of the pilots: a steady stringent trend in Shenzhen, Hubei, and Chongqing, a steady loose trend in Guangdong and Tianjin, and no clear trend in Shanghai and Beijing.

\section{Scope and Coverage}

An important premise for an ETS is to define the scope and coverage, or rather establish which greenhouse gases should be covered, which sectors should be included, and what the threshold should be for the emitters involved. Most of China's pilots only cover $\mathrm{CO}_{2}$ emissions, with the exception of Chongqing, which includes all of the six greenhouse gases, i.e., $\mathrm{CO}_{2}, \mathrm{CH}_{4}, \mathrm{~N}_{2} \mathrm{O}$, HFCs, PFCs, and $\mathrm{SF}_{6}$.

The emissions sources covered in China's ETS pilots are legal entities rather than installations or facilities, which is fundamentally different from the ETS in the EU and other emissions trading systems [15]. All of the pilots include a common set of sectors: iron and steel, heat and electricity production, petrochemicals and chemicals, nonferrous metals, pulp and paper, and glass and cement. However, there are still some differences due to the differing industry structures and regional size. For instance, aviation is included in Shanghai, automobile manufacturing is included in Hubei, oil and gas exploration sector in Tianjin, public transportation in Shenzhen, and over 40 different sectors in Beijing.

Coverage thresholds vary substantially across the pilots, with most covering firms with annual emissions above 10,000 or $20,000 \mathrm{tCO}_{2} \mathrm{e}$; however, Hubei is the highest at $60,000 \mathrm{tCO}_{2} \mathrm{e}$, and Shenzhen is the lowest at
$3,000 \mathrm{tCO}_{2}$ e. This is because Hubei is a large province dominated by large-scale, carbon-intensive industries such as chemical firms, while Shenzhen is an economic zone dominated by service sectors with low emissions. Under different thresholds, the total number of covered entities in each of the pilots varies from 112 in Tianjin to 947 in Beijing.

In the forthcoming national scheme, the ETS will cover firms with annual carbon emissions above 20,000 $\mathrm{tCO}_{2} \mathrm{e}$ in petrochemical, chemical, building materials, steel, non-ferrous metals, paper, electricity, and aviation industries.

\section{Allowance Allocation}

The allocation of carbon allowances is of vital importance for the operation and performance of ETS pilots. Free allocation via benchmarking or grandfathering and auctioning are methods generally adopted, otherwise it is wrongly described. The vast majority of the pilots adopt free allocation, though several are moving toward a combination of the two approaches $[16,17]$. Guangdong was the first pilot using auctioning to allocate initial allowances: only if enterprises pay for some portion of the allowances $(3 \%, 5 \%$, and $10 \%$ respectively in 2013, 2014, and 2015) can they receive the rest for free. In Shenzhen, up to 3\% of allowances can be auctioned [18]. However, only one auction has taken place (in June 2014). Several pilots, such as Hubei and Shenzhen, retain a small share of allowances as a reserve, which can be put on the market for price discovery and control.

Grandfathering, which is based on historical emissions using a baseline year, is widely used in most pilot sectors, with the exception of Shenzhen, which only uses benchmarking for allocation [13]. Shanghai improves grandfathering and provides support for enterprises' early mitigation actions by considering the participants' previous efforts to reduce emissions. However, allocation methodology for the power sector varies among ETS pilots [19]. Shanghai, Shenzhen, Tianjin, and Guangdong use benchmarks on the basis of production. While Beijing uses grandfathering to allocate allowances based on historical intensities, Tianjin and Guangdong adjust the allowances by adding a sector-level reduction factor and prosperity index.

Temporal flexibility provisions such as banking [20] can provide the option to take advantage of mitigation and reduce compliance costs: regulated entities would hold surplus allowances from previous trading periods when mitigation may have been easier, while surrendering them to future compliance periods when they may be more expensive. However, borrowing next year's allowances for compliance or sales is strictly prohibited among all of the pilots. For example, Hubei requires that the allowances that are not used for transactions during the current compliance period be canceled. However, Shanghai allows banking across compliance periods. 


\section{Offsets}

To encourage cost-effective measures in regions and sectors not directly covered by the ETS, all pilots are allowed to adopt the Chinese Certified Emissions Reductions (CCERs) ${ }^{2}$ for a limited amount of carbon offsets. However, the pilots set various quantitative and qualitative boundaries in the time, type, and source of CCERs for the offset, resulting in a different amount of eligible CCER records (Hubei with 56 records, much higher than the other pilots, while Tianjin had the fewest, only 3 records). Quantitatively, the covered entities in Shanghai and Beijing are allowed to use CCERs to offset up to $5 \%$ of the annual allowances (Shanghai only allowed $1 \%$ in 2016), Chongqing permits carbon offsetting of up to $8 \%$, while Guangdong, Shenzhen, Tianjin, and Hubei allow up to $10 \%$.

The seven pilots also set different qualitative limits of carbon offsetting. Most pilots only approve reductions achieved after the beginning of 2013, with the exception of Chongqing, which set 2010 as the point of reference. As to the CCER types, Beijing allows verified emissions reductions from energy-saving projects and forest carbon sink projects, while Tianjin only allows $\mathrm{CO}_{2}$ reduction projects. As to the regional sources, Hubei only approves CCER projects within the province for compliance, Beijing has determined that CCERs generated outside BJ shall not exceed $2.5 \%$ of the quotas issued for that year, while Shenzhen accepts renewable energy and new energy projects in most provinces across the country.

\section{$M R V$}

A credible, inclusive, and transparent monitoring, reporting, and verification (MRV) mechanism is crucial for an ETS. There are two typical methods of monitoring: real-time approach and emission-factor-based calculation approach. Although continuous real-time monitoring is more accurate, it requires significant investment in equipment and technology. The emission-factor approach, recommended by the Intergovernmental Panel on Climate Change (IPCC), is widely adopted, and also used by China's ETS pilots.

All covered entities in China's ETS are required to report emissions each year, and the reports submitted must be validated by an accredited third party appointed by local governments. The NDRC reviews annual carbon emissions and verifies any discrepancies in the reports. The NDRC has released three batches of 24 greenhouse gas reporting guidelines and regulations on monitoring and reporting for ten sectors, including power plants, power grid, iron and steel, chemical, electrolytic

\footnotetext{
2 CCER is a type of emissions unit (or carbon credit) issued by the Clean Development Mechanism (CDM) for emission reductions achieved by CDM projects and verified by China on a national basis.
}

aluminum, magnesium smelting, glass, cement, ceramics, and aviation.

As no national guidance document is issued for the pilot programs, the seven pilots set their own regional MRV guidelines, respectively. The general guidelines set out GHG accounting and reporting methodologies and emission factors for different energy sources and chemical processes for major covered sectors. Beyond that, three pilots (Shanghai, Tianjin, and Hubei) require specific information on the monitoring methods, scope, frequency, and the person responsible.

\section{Non-Compliance Penalties}

Penalties are an effective means to ensure that regulated entities comply with the ETS rules. All pilots have their own set penalties for non-compliant entities that fail to surrender sufficient emissions at the end of the compliance year, or fail to submit monitoring plans or emission reports on a specified date, or submit counterfeit data and reports.

Most pilots will order the non-compliant entities to complete their commitment within a set time frame, always within a month or so. If the entities still fail to meet the obligation, they face several kinds of penalties. The first is the deduction of allowances in the following year. For example, enterprises in Guangdong and Hubei will have twice the amount of allowances deducted from next year's allocation. The second penalty for noncompliant enterprises is a fine equivalent to several times (e.g., Shenzhen with three times, Beijing with five times) their emissions shortfall at the average carbon price, ranging from 50 to 150 thousand $\mathrm{CNY}$. Other measures include the closure of access to government energy conservation funds or subsidies, and downgrading the entity's credit rating.

Comparatively, penalties in Chongqing and Tianjin are relatively low, with no direct economic or substantive punishment on non-compliant entities. The only penalty for the two pilots is that those that failed to comply are not allowed to enjoy government support concerning low-interest loans and financial subsidies on energy conservation and environmental protection for the following three years.

\section{Performance of China's ETS Pilots}

\section{Carbon Emission Reductions}

The most important performance for any ETS is to see whether there is a reduction in emissions. As shown in Table 1, there is a significant reduction in $\mathrm{CO}_{2}$ intensity in all the pilots in 2015 compared to 2013, with the highest reduction of $33.33 \%$ (from 0.060 to 0.040 $\mathrm{t} / 1000 \mathrm{CNY}$ ) in Beijing. However, the reduction rate in the seven pilots varies. Tianjin, Shanghai, Chongqing, and Guangdong, witnessed a reduction rate of $19.29 \%$ (from 0.140 to 0.113 ), $17.74 \%$ (from 0.124 to 0.102 ), $21.19 \%$ (from 0.118 to 0.093 ), and $13.83 \%$ (from 0.094 to 0.081 ), 


\begin{tabular}{|c|c|c|c|c|c|c|c|c|}
\hline \multicolumn{2}{|c|}{ 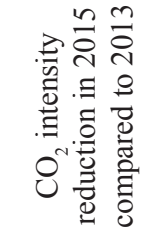 } & $\begin{array}{l}\stackrel{0}{\circ} \\
\stackrel{0}{0}\end{array}$ & $\begin{array}{l}\stackrel{0}{0} \\
\infty \\
\dot{\sim}\end{array}$ & 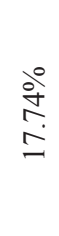 & 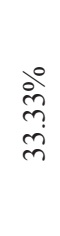 & $\begin{array}{l}\stackrel{\circ}{े} \\
\stackrel{2}{2}\end{array}$ & $\begin{array}{l}\stackrel{0}{0} \\
\dot{0}\end{array}$ & 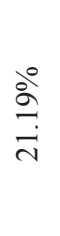 \\
\hline \multirow{3}{*}{$\stackrel{n}{\stackrel{\sim}{\sim}}$} & 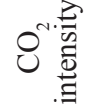 & $\begin{array}{l}\text { ơ } \\
0 \\
0\end{array}$ & $\begin{array}{l}\vec{\infty} \\
0 \\
0\end{array}$ & $\begin{array}{l}\text { Ŝ } \\
0 \\
0\end{array}$ & $\begin{array}{l}\text { o } \\
0 \\
0\end{array}$ & $\stackrel{m}{=}$ & $\stackrel{\Xi}{=}$ & $\begin{array}{l}\tilde{o} \\
0 \\
0\end{array}$ \\
\hline & 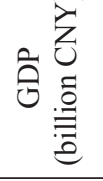 & $\begin{array}{l}\stackrel{n}{n} \\
\stackrel{\text { İ }}{i}\end{array}$ & 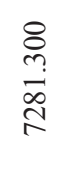 & $\begin{array}{l}n \\
\infty \\
\infty \\
\stackrel{0}{0} \\
\infty \\
\sim\end{array}$ & 守 & $\begin{array}{l}\vec{\partial} \\
\dot{0} \\
\hat{\delta} \\
\underline{-}\end{array}$ & $\begin{array}{l}\overrightarrow{0} \\
\dot{\hat{n}} \\
\hat{\alpha}\end{array}$ & $\underset{\substack{\hat{N}\\
}}{n}$ \\
\hline & 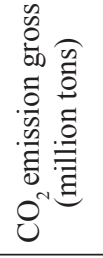 & $\underset{\infty}{\stackrel{0}{=}}$ & $\begin{array}{l}\stackrel{2}{\infty} \\
\stackrel{8}{\circ} \\
\stackrel{\infty}{n}\end{array}$ & 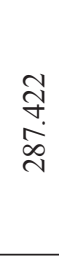 & 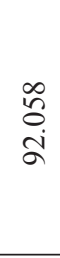 & $\begin{array}{l}\mathbb{1} \\
\infty \\
\infty \\
\infty \\
\infty \\
-1\end{array}$ & $\begin{array}{r}\hat{n} \\
\dot{n} \\
\stackrel{n}{n}\end{array}$ & $\begin{array}{l}\vec{I} \\
\overrightarrow{0} \\
\stackrel{0}{J}\end{array}$ \\
\hline \multirow{3}{*}{$\stackrel{\vec{D}}{\vec{i}}$} & 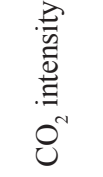 & $\vec{d}$ & $\begin{array}{l}0 \\
\& \\
0 \\
0\end{array}$ & $\stackrel{2}{\circ}$ & $\begin{array}{l}\tilde{n} \\
0 \\
0\end{array}$ & $\begin{array}{l}\stackrel{ \pm}{I} \\
\stackrel{0}{0}\end{array}$ & $\stackrel{2}{\stackrel{0}{0}}$ & $\begin{array}{l}\vec{\exists} \\
\end{array}$ \\
\hline & 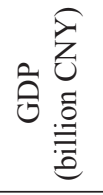 & $\begin{array}{l}\infty \\
\infty \\
\infty \\
\stackrel{+}{+} \\
m\end{array}$ & 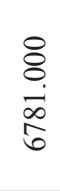 & 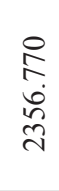 & 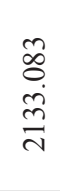 & $\begin{array}{l}\tilde{\hat{\sigma}} \\
\dot{i} \\
\hat{n}\end{array}$ & 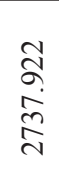 & 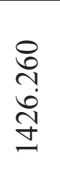 \\
\hline & 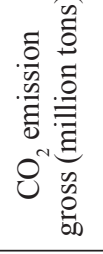 & $\begin{array}{l}\stackrel{O}{+} \\
\underset{I}{+}\end{array}$ & $\begin{array}{l}\stackrel{8}{0} \\
\dot{\infty} \\
\infty \\
\infty\end{array}$ & $\begin{array}{l}\overrightarrow{0} \\
\stackrel{+}{+} \\
\stackrel{+}{\sim}\end{array}$ & 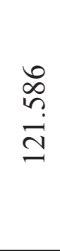 & 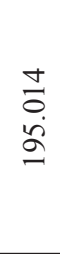 & $\begin{array}{l}m \\
\infty \\
n \\
n \\
n\end{array}$ & $\begin{array}{l}\frac{n}{m} \\
\infty \\
\infty \\
n\end{array}$ \\
\hline \multirow{3}{*}{$\stackrel{m}{\stackrel{2}{c}}$} & 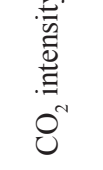 & $\stackrel{\tilde{O}}{\stackrel{\tilde{O}}{0}}$ & $\begin{array}{l}\text { ò } \\
\text { Oे }\end{array}$ & $\frac{d}{\stackrel{J}{0}}$ & $\begin{array}{l}8 \\
0 \\
0\end{array}$ & $\frac{P}{0}$ & 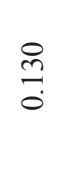 & $\stackrel{\infty}{=}$ \\
\hline & 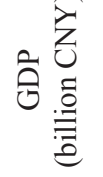 & $\begin{array}{l}\frac{1}{b} \\
\stackrel{i}{\pi} \\
\tilde{n}\end{array}$ & 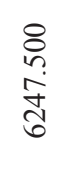 & $\begin{array}{l}\frac{n}{\infty} \\
\stackrel{\infty}{a} \\
\vec{N}\end{array}$ & $\begin{array}{l}\vec{\infty} \\
\stackrel{0}{0} \\
\dot{\infty} \\
\stackrel{0}{0}\end{array}$ & $\begin{array}{l}\overrightarrow{\tilde{H}} \\
\dot{J} \\
\dot{J}\end{array}$ & $\begin{array}{l}\hat{\infty} \\
\stackrel{\alpha}{a} \\
\stackrel{+}{d}\end{array}$ & 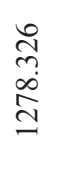 \\
\hline & 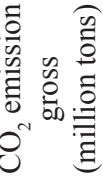 & $\begin{array}{l}\stackrel{8}{0} \\
\dot{ \pm}\end{array}$ & 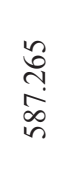 & $\begin{array}{l}\stackrel{n}{+} \\
\stackrel{2}{2} \\
\stackrel{2}{N}\end{array}$ & $\begin{array}{l}2 \\
\infty \\
\infty \\
\infty \\
=\end{array}$ & $\begin{array}{l}\infty \\
\stackrel{\infty}{0} \\
\stackrel{\text { ¿े }}{~}\end{array}$ & $\begin{array}{l}\text { ते } \\
\text { ते } \\
\text { ते }\end{array}$ & 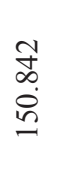 \\
\hline & $\frac{\overrightarrow{0}}{\vec{n}}$ & $\begin{array}{l}\text { D̃ } \\
\frac{\bar{N}}{\bar{D}} \\
\text { E }\end{array}$ & 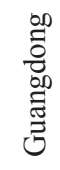 & $\begin{array}{l}\overrightarrow{\widetilde{J}} \\
\overline{b 0} \\
\overline{\tilde{E}} \\
\bar{w}\end{array}$ & : & :寻 & 离 & 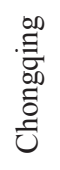 \\
\hline
\end{tabular}

respectively; while Shenzhen and Hubei only witnessed a decline with the rate of $6.98 \%$ (from 0.043 to 0.040 ) and $10.00 \%$ (from 0.130 to 0.117 ). Also, what should be noted is, even though the ETS is a major instrument for meeting carbon intensity targets, it is not the only one [21]. Other policies such as environmental taxes may also contribute to carbon reduction.

\section{Carbon market performance}

With only three years of use, China's ETS is still in its infant stage, characterized by low carbon prices with severe temporal fluctuation and low level of liquidity alongside high compliance rates.

With most allowances excessively allocated at the pilot stage, the carbon prices are relatively low [22], with an average price of CNY33.38, 15.14, 18.35, 50.69, 16.76, 20.63, and 14.33 for Shenzhen, Guangdong, Shanghai, Beijing, Tianjin, Hubei, and Chongqing, respectively far less than the threshold of CNY200-300 per $\mathrm{tCO}_{2} \mathrm{e}$ to stimulate firms to engage in carbon trade and reduction [23]. The trading price somewhat reflects the regulation stringency: Beijing and Shenzhen rank the highest for their most stringent regulation, while Chongqing and Guangdong rank the lowest for their abundant allowances. Though at a low level, it has witnessed wild variations in carbon prices in different regions. Carbon prices range from approximately CNY3.28 per $\mathrm{tCO}_{2} \mathrm{e}$ in Chongqing to CNY122.97 in Shenzhen. Shenzhen experienced the most dramatic price fluctuation in its early stage, starting from CNY 29 per $\mathrm{tCO}_{2}$ e to a peak of CNY122.97 in four months. The price in early April of 2014 in Shanghai was CNY 5.40 per $\mathrm{tCO}_{2} \mathrm{e}-$ only $20 \%$ of the opening price. Most of the carbon prices were trending downward until the end of 2016, which witnessed an upward shift with the expectation of a nationwide ETS in 2017. Another trend is that carbon prices increased before the end of each year's compliance deadline, while dramatically declining after that date. For example, carbon prices in Guangdong, Shanghai, and other regions almost all experienced a huge decline after the compliance of that year. This seasonal fluctuation may be because firms in shortage of quota only buy it when the compliance date approaches, which raises the carbon price.

A healthy level of liquidity, or to say, trading volumes, is important for both buyers and sellers in the ETS pilots [24]. However, market liquidity is quite low and with a strong temporal fluctuation and regional difference in the pilots [25]. As shown in Table 2, by the end of 2016, a cumulative $86.16 \mathrm{MtCO}_{2} \mathrm{e}$ has been transacted in the seven pilots for a value of 2004.48 million CNY, with only an average of $23.26 \mathrm{MtCO}_{2} \mathrm{e}$ per trading day.

Among the pilots, the Hubei market is the most active, accounting for $35.03 \%$ of the total trading volume, with $34.04 \mathrm{MtCO}_{2}$ e traded at a value of 702.23 million CNY (see Table 2). Guangdong and Shenzhen come in second and third, with 19.80 and $17.44 \mathrm{MtCO}_{2}$ e traded, respectively. In contrast, Chongqing and Tianjin are the most inactive ones, with only 0.73 and $1.84 \mathrm{MtCO}_{2} \mathrm{e}$, 
Table 2. Emissions trading volume and price of the seven pilots (until Dec. 31, 2016).

\begin{tabular}{|c|c|c|c|c|c|}
\hline Pilot & Days of trading & $\begin{array}{c}\text { Total cap } \\
\text { (million tons) }\end{array}$ & $\begin{array}{c}\text { Trade volume } \\
\text { (million tons) }\end{array}$ & $\begin{array}{c}\text { Trading amount } \\
\text { (million CNY) }\end{array}$ & $\begin{array}{c}\text { Average price } \\
\text { (CNY/tons) }\end{array}$ \\
\hline Shenzhen & 1120 & 121 & 17.44 & 582.18 & 33.38 \\
\hline Guangdong & 937 & 1590 & 19.80 & 299.80 & 15.14 \\
\hline Shanghai & 937 & 605 & 7.56 & 138.69 & 18.35 \\
\hline Beijing & 958 & 191 & 4.74 & 240.28 & 50.69 \\
\hline Tianjin & 930 & 480 & 1.84 & 30.84 & 16.76 \\
\hline Hubei & 833 & 1182 & 34.04 & 702.23 & 20.63 \\
\hline Chongqing & 755 & 441 & 0.73 & 10.46 & 14.33 \\
\hline Total & - & 4491 & 86.16 & 2004.48 & 23.26 \\
\hline
\end{tabular}

Source: DRC of each pilot; http://www.tanjiaoyi.com/

respectively, for the whole pilot stage. The total trading volume constitutes only a small fraction of the total number of available allowance. For example, the trading volume in Chongqing only equals $0.17 \%$ of the total allowance available in the market. Chongqing is the most inactive, the reason perhaps being that it is in the west with abundant natural resources and environmental pollution is not a serious problem.

The historical transaction data showed that the largest transactions mostly occurred around the annual compliance deadline. The following is the proportion of the volume trade from May to July, the compliance period, in each year. More than $40 \%$ of the transactions occurred during May-July in almost all of the pilots, with Chongqing a record high at $100 \%$ in 2014. In Tianjin, more than $90 \%$ of the transactions are concentrated during the compliance period from 2014 to 2016. Interestingly, Chongqing witnessed a high proportion of transactions in May-July in 2014 and 2015 (100\% and $84.72 \%$, respectively); however, no transactions occurred during the compliance period in 2016. Although it does not affect the overall emission reduction targets, such variation would result in higher costs for firms to obtain the same compliance. However, this situation has been improved in Guangdong, Chongqing, and Tianjin, where the proportion of the volume trade from other months gradually increased in 2016, and the trading volume tends to be more stable throughout the whole year.

\section{Compliance}

Compliance is critical for an ETS pilot to achieve its goals. A regulated entity must annually surrender emissions allowances equal to its verified level of emissions. Shanghai, Guangdong, and Shenzhen performed well after somewhat extended compliance deadlines (less than one month). Shanghai is the only pilot that achieved $100 \%$ compliance rates for three years. Guangdong achieved compliance rates of $98.9 \%, 100 \%$, and $100 \%$ for the three compliance periods, respectively, while Shenzhen achieved compliance rates of $99.4 \%$,
$99.7 \%$, and $99.84 \%$. Chongqing, the latest operated pilot, has the lowest rate of compliance at only $70 \%$ for the first compliance year (2014-2015), while the 2015-2016 compliance rate is not published yet. It can also be seen that the compliance rate is continuously going up for most of the pilots in the three consecutive years (though Beijing witnessed a downward trend from $100 \%$ in 2015 to $97.7 \%$ in 2016, its covered entities soared from 543 to 947). Although imbalanced, their excellent compliance performance in the pilot stage is an encouraging sign for the national scheme.

\section{Problems of China's ETS Pilots}

Although China's ETS has made great progress in the pilot phase, there are still many problems for establishing a national carbon market. China's ETS pilots are characterized by an over-allocation of emission allowances, inadequate legal and regulatory infrastructure, an underdeveloped carbon financial market, and poor market transparency.

\section{Over-Allocation of Emission Allowances}

The first stage of China's ETS pilots, a learning period prior to the national scheme, was intended to have a gradual start without too stringent emissions caps. For example, the number of allowances allocated in Hubei turned out to be more than actual emissions in 2013, and the allowances in Chongqing is the sum of the highest emissions between 2008 and 2012, which may make it unnecessary for regulated entities to invest in emissions abatement to achieve the reduction goals. The over-allocation and insufficient institutional infrastructure leads to a scarce market demand and a low allowance price, weakening investments in low-carbon technology. As of December 31, 2016, the total trading volumes of the Shanghai and Beijing (the two major cities in China) totaled 7.56 and 4.74 $\mathrm{MtCO}_{2} \mathrm{e}$, respectively - far less than that of the ETS in the EU. 


\section{Inadequate Legal and Regulatory Infrastructure}

Legislation and regulation is fundamental to establishing an efficient carbon market. Although there are some relevant policies and rules, China's legal and regulatory infrastructure for the ETS is inadequate and far from complete. Currently, the management of China's ETS is led by the NDRC, which acts not only as the leader but also as the rule maker and executor in China's carbon trading [26]. There lacks a higher national level of legislation of the ETS by the National People's Congress [27]. The key aspects of enabling a sound ETS, e.g., caps and allowances, trading rules, monitoring, verification, emissions data collection, enforcement, and punishment, should be supported by a legal and regulatory system [28].

\section{Underdevelopment of Carbon Financial Markets}

The carbon finance market is another important factor for a healthy and active carbon market [28]. However, in China financial institutions are not yet familiar with operating carbon finance, carbon project development, trading rules, or international regulations, and they have no incentives for the potential risks such as liquidity risks and information asymmetry risks. The lack of capabilities and incentives of financial institutions to engage in the carbon market makes it difficult to attract businesses and financial institutions. As a result, there are seldom any other institutions involved except for a small number of banks in the financial sector focusing on carbon finance, not to mention the establishment of a sound carbon fund, carbon insurance, carbon investment banks, carbon rating companies, and other carbon financial institution systems. On the supply side, the China Carbon Exchange is still in the preliminary stage. For the prosperity of carbon trading, the exchange must have the ability to allow derivatives from the trading and security business, but the central government on derivatives and securities issuance does not propose a clear program to encourage its development, largely to take into account the risk management issues [29]. Underdevelopment of a carbon finance market prevents stakeholders from becoming participants and providing a powerful boost for market activity.

\section{Poor Market Transparency}

The construction of an effective ETS requires transparency in information disclosure. However, the lack of an effective information management and disclosure system makes the transparency of China's carbon market a matter of concern. China has not set up relevant policies, regulations, convenient integrative platforms, nor channels for ETS information disclosure, which makes it difficult to obtain necessary and timely information for carbon stakeholders. Most regulated entities are unfamiliar with and lack a carbon emission management system, and are reluctant to disclose relevant information. As a result, the information required for carbon disclosure is fragmented or partially missing within the enterprise. All the above resulted in an opaque carbon market with inadequate, lagging, and symbolic information disclosure, which prevents regulators, investors, researchers, and the public from accurate knowledge and, finally, better ETS development.

\section{Conclusions and Proposals for a National ETS}

China's national carbon market was expected to be the world's largest when it began trading in late 2017. With U.S. President Trump's refusal of the Paris agreement on Climate Change, China's national ETS is attracting particular attention and is expected to significantly contribute to GHG emissions reduction. China has designed and implemented seven ETS pilots in a remarkably short amount of time since 2013 and is moving toward a nationwide system in 2017. Though this is substantial progress, there are still many problems unsolved for a national ETS. We conclude this paper by proposing recommendations for the construction of a national ETS, aiming at both emissions reduction and the benefits of the mass.

First, the benefits of the mass should be fully considered. In building a carbon trading system, we must not only consider carbon emission reductions and transactions, but also the interests of the general public and further balance the relationship between energy conservation and emission reduction and people's needs.

Second, a national level ETS legislation is in urgent need, since more frequent and intense disputes could emerge as the ETS expands beyond the institutional jurisdiction of administrative regions. While several policy documents have confirmed the intent of developing a national ETS, few state-level rules have been issued specific to the system's design and operation. The "interim measures for carbon emissions trading" released by the NDRC, the only national-level ETS guideline, should be elevated to a state council regulation, ideally, to national law, to ensure the authority of ETS at the national level. There should also be a clear responsibility for both central and local regulators [30]. The former should set national regulations to ensure the same rules regarding coverage and scope, allocation of allowances, uniform standards for MRV, and compliance across provinces; while the latter, the local governments should take the responsibility of implementing or even setting stricter regulations than the national rules. Watchdog institutions should also be designed to monitor trade once the national exchanges have been developed.

Third, an efficient cap setting is essential. An over-tight cap will impose undue pressure on covered entities, while an over-loose cap will lead to no carbon reduction or inactive trading. Chinese regulators should scientifically design and gradually tighten the cap until 
the carbon price matches the social cost of carbon [31], an estimate of the economic damage associated with an increase in one metric ton of $\mathrm{CO}_{2}$ emissions in a given year [32]. As for the specific design, the cap should be set through a top-down approach by the central government to avoid a loose target due to local protectionism.

Fourth, an independent and transparent carbon MRV is crucial. A well working ETS depends on a foundation of accurate, reliable, and comparable data. It is a prerequisite to ensure multiple stakeholders and link fragmented ETS pilots to a nationwide system. Chinese regulators should invite and supervise thirdparty agencies to facilitate monitoring, reporting, and verification, while the agencies should provide technical support and training to covered entities. Also, covered entities should invest in MRV capacity building to prepare for the national ETS [33]. Another important issue is to release such information as widely as possible - not only to those relevant governments and regulated entities but also to the public, to supervise and help promote carbon reduction and emissions trading.

Fifth, price management and market stabilization provisions are of vital importance [5]. Market instability and price uncertainty are expected to become even bigger issues in a national ETS. An appropriate floor price, as well as ceiling price, should be established to reduce carbon price uncertainty and promote market stabilization. However, setting an exact price is not an easy task. Detailed regional, sectoral, and nationwide studies on carbon abatement can provide some insights.

Finally, the coordination of multiple energy and climate policies is essential. Currently, several ministries are involved in setting regulations on energy use and environmental protection, such as the Environmental Protection Ministry, Transportation Ministry, etc. This would increase the chances of policy overlap, inconsistency, and confusion, which reduces the effectiveness of ETS. Thus it is important to systematically examine carbon-related policies, identify interactions between ETS and other policies, and develop coordinating mechanisms across multiple government agencies to avoid redundancy - for example by minimizing overlap between sectors regulated by the ETS and those subject to direct regulation [30].

\section{Acknowledgements}

This work was supported by the National Natural Science Foundation of China (grant Nos. 71672194, 71372064, and 71431006), Key Projects of Philosophy and Social Sciences Research of Ministry of Education of China (grant No. 16JZD013), the Natural Science Foundation of Hunan (grant No. 2017JJ3398), the Social Science Foundation of Hunan (grant No. 17YBA407), and Innovative Driven Projects of Central South University (grant Nos. 2015CX010 and 2016CX041).

\section{Conflict of Interest}

The authors declare no conflict of interest.

\section{References}

1. BP (British Petroleum).Statistical Review of World Energy 2016. BP, London,.2016.

2. JOTZO F., LÖSCHEL A. Emissions trading in China: Emerging experiences and international lessons.Energ. Policy 75, 3, 2014.

3. LI D., HUANG M., REN S., CHEN X., NING L. Environmental legitimacy, green innovation, and corporate carbon disclosure: Evidence from CDP China 100. J. Bus. Ethics., 150 (4), 1089, 2018.

4. XINHUANET. Speech on Copenhagen COP15 by Premier Wen Jiabao. Availableat:http://news.xinhuanet.com/ world/2009-12/19/content $\% 512668033 . h t m .2009$.

5. CUI L.B., FAN Y., ZHU L., BI Q.H. How will the emissions trading scheme save cost for achieving China's 2020 carbon intensity reduction target?.Appl. Energ., 136, 1043,2014.

6. LI W., LU C. The research on setting a unified interval of carbon price benchmark in the national carbon trading market of China. Appl. Energ., 155, 728, 2015.

7. DUAN M., PANG T., ZHANG X. Review of carbon emissions trading pilots in China. Energ \& ENVIRON, 25 (3-4), 527, 2014.

8. YANG L., WANG J., SHI J. Can China meet its 2020 economic growth and carbon emissions reduction targets?. J. Clean. Pro., 142, 993, 2017.

9. ZHANG D., RAUSCH S., KARPLUS V.J., ZHANG X. Quantifying regional economic impacts of $\mathrm{CO}_{2}$ intensity targets in China. Energ. Econ., 40, 687, 2013.

10. JIANG J., XIE D., YE B., SHEN B., CHEN Z. Research on China's cap-and-trade carbon emission trading scheme: Overview and outlook. Appl. Energ., 178, 902, 2016.

11. DE PERTHUIS C., TROTIGNON R.Governance of $\mathrm{CO}_{2}$ markets: lessons from the EU ETS. Energ. Policy, 75, 100, 2014.

12. CHANG K., CHANG H. Cutting $\mathrm{CO}_{2}$ intensity targets of interprovincial emissions trading in China. Appl. Energ., 163, 211, 2016

13. YI B.W., XU J.H., FAN Y. Determining factors and diverse scenarios of $\mathrm{CO}_{2}$ emissions intensity reduction to achieve the $40-45 \%$ target by 2020 in China - a historical and prospective analysis for the period 2005-2020. J. Clean. Pro., 122, 87, 2016.

14. Shenzhen DRC(Development and Reform Commission). Interim Measures of Shenzhen Municipality on the administration of carbon emissions trading, April 2, 2014.

15. PANG T., DUAN M. Cap setting and allowance allocation in China's emissions trading pilot programmes: special issues and innovative solutions. Clim. Policy, 16 (7), 815, 2016.

16. ZHANG Z. Carbon emissions trading in China: the evolution from pilots to a nationwide scheme. Clim. Policy, 15(sup1), S104, 2015.

17. LI R., TANG B.J. Initial carbon quota allocation methods of power sectors: a China case study. Nat. Hazards., 84 (2), 1075, 2016.

18. TANG L., WU J., YU,L., BAO Q. Carbon allowance auction design of China's emissions trading scheme: A multi-agent-based approach. Energ. Policy., 102, 30, 2017. 
19. WANG W., LUO Y., XIE P., LUO Z., ZHAO D. The key elements analysis of Guangdong \& Shenzhen ETS \& tips for China national ETS construction. Chinese J. P. Resour \& Environ., 14 (4), 282, 2016.

20. ZHAO R., MIN N., GENG Y., HE Y. Allocation of carbon emissions among industries/sectors: An emissions intensity reduction constrained approach. J. Clean. Pro., 142, 3083, 2017.

21. ICAP(International Carbon Action Partnership). Emissions trading worldwide.https://icapcarbonaction.com/ $\mathrm{zh} /$ ?option=com_attach\&task=download\&id=448., 2017.

22. HAO Y., LIAO H., WEI Y.M. Is China's carbon reduction target allocation reasonable? An analysis based on carbon intensity convergence. Appl. Energ., 142, 229, 2015

23. QI S., WANG B. Fundamental issues and solutions in the design of China's ETS pilots: allowance allocation, price mechanism and state-owned key enterprises. Chinese J. P. RESOUR \& ENVIRON., 11 (1), 26, 2013.

24. FAN Y., WU J., XIA Y., LIU J.Y. How will a nationwide carbon market affect regional economies and efficiency of $\mathrm{CO}_{2}$ emission reduction in China? China. Econ. Rev., 38, $151,2016$.

25. CHEN J., CHENG S., SONG M., WU Y. A carbon emissions reduction index: Integrating the volume and allocation of regional emissions. Appl. Energ., 184, 1154, 2016.

26. ZHAO X.G., JIANG G.W., NIE D., CHEN H. How to improve the market efficiency of carbon trading: a perspective of China. Renew. Sust. Energ. Rev., 59, 1229, 2016.
27. LIU L., CHEN C., ZHAO Y., ZHAO E. China's carbonemissions trading:Overview, challenges and future..Renew. Sust. Energ. Rev. 49, 254, 2015.

28. VILLORIA-SAEZ P., TAM V.W., DEL RÍO MERINO M., ARREBOLA C.V., WANG X. Effectiveness of greenhousegas Emission Trading Schemes implementation: a review on legislations. J. Clean. Prod., 127, 49, 2016.

29. LO A.Y. Challenges to the development of carbon markets in China. Clim. Policy., 16 (1), 109, 2016.

30. CONG R., LO A.Y. Emission trading and carbon market performance in Shenzhen, China. Appl. Energ. 193, 414, 2017.

31. ZHANG D., KARPLUS V.J., CASSISA C., ZHANG X. Emissions trading in China: Progress and prospects. Energ. Policy, 75, 9, 2014.

32. ZHOU X., FAN L.W., ZHOU P. Marginal $\mathrm{CO}_{2}$ abatement costs: findings from alternative shadow price estimates for Shanghai industrial sectors. Energ. Policy, 77, 109, 2015.

33. EPA (US Environmental Protection Agency).The Social Cost of Carbon. http://www3.epa.gov/climatechange/ EPAACTIVITIES/ECONOMICS/SCC.HTML., 2015.

34. MUNNINGS C., MORGENSTERN R.D., WANG Z., LIU X. Assessing the design of three carbon trading pilot programs in China. Energ. Policy, 96, 688, 2016. 
